\title{
ADULT PRESENTATION OF DYKE DAVIDOFF MASSON SYNDROME WITH SCHIZOAFFECTIVE DISORDER - A CASE REPORT
}

\author{
MK Dinesh Kumar ${ }^{1 *}$, Denver Steven Pinto ${ }^{2}$ \\ ${ }^{1}$ Senior Resident, Dept. of Psychiatry, Malabar Medical College, Modakkallur. \\ ${ }^{2}$ Assistant Professor, Dept. of Radiology, Malabar Medical College, Modakkalur. \\ *Correspondence: Dept. of Psychiatry, Malabar Medical College, Modakkallur. PIN: 673315. E-mail: dineshmk2010@gmail.com
}

\begin{abstract}
Dyke Davidoff Masson syndrome (DDMS) is a rare disease with characteristic radiological features, seizures, mental retardation, facial asymmetry, and psychiatric manifestations. Here, we report a case of a 50-year-old female who had a refractory seizure disorder and schizoaffective disorder. Radiological investigation revealed the features of DDMS.
\end{abstract}

Keywords: Dyke Davidoff Masson Syndrome, Cerebral hemiatrophy, Schizoaffective disorder

\section{INTRODUCTION}

In 1933, Dyke et al. ${ }^{1}$ reported the characteristic bone changes associated with Dyke Davidoff Masson Syndrome (DDMS) in their series of nine patients who had infantile hemiplegia. They described cerebral hemiatrophy which consisted of ipsilateral thickening of the cranial wall on the same side as the cerebral lesion. These lesions were accompanied by hypertrophy of the frontal and ethmoid sinuses and the air cells of the temporal bone. Encephalogram studies of the patients showed enlargement of lateral ventricles. The adult presentation of this syndrome is quite rare and few of them present with psychiatric comorbidity. The psychiatric manifestations could be depression ${ }^{2}$ or schizoaffective disorder. ${ }^{3,4}$

\section{CASE REPORT}

A 50-year-old unmarried lady, belonging to the low socio-economic status, presented with her mother who reported that the patient, who is on treatment for seizure disorder since childhood, has behavioral problems for a few months. The patient has been complaining that she could hear voices which were abusive and commanding her to commit suicide. At times, the patient had threatened to kill her mother and to end her own life.

The patient had normal development in her first year, till she had a serious brain infection for which she was hospitalized for two weeks. Details regarding this were not available. Subsequently, the patient developed seizure disorder for which she has been on antiepileptics. She also showed much slower development in her childhood and could not complete her primary education. She could dress on her own and maintain hygiene. She was on treatment for hypothyroidism. Currently, she was on Phenytoin sodium, Phenobarbital, and Thyroid hormone. Interviewing her was difficult as she was uncooperative, and she often stated that she continuously heard the voices of her dead relatives abusing her and asking her to end her life. She also expressed that she had lost hope for living, that she was depressed, and that she wanted to die. The mother reported that she had disturbed sleep. 
Considering the presence of persistent psychotic symptoms and the history of periodic affective, obsessive, and depressive symptoms which used to last more than two weeks, a diagnosis of schizoaffective disorder was made based on the ICD-10 criteria.

Evaluation by a neurologist did not reveal any major neurological deficits. The patient was not cooperative for a detailed examination. She had difficulty in walking, but her gait was steady, and no visible ataxia or other gait disturbances were noted. On neurological examination, the cranial nerves function was normal. She had a power of $5 / 5$ in all her limbs, and her tone was normal. She had sluggish deep tendon reflexes throughout her upper and lower limbs. Plantars were flexor on both sides.

She was initially treated with atypical antipsychotics, Risperidone (up to $12 \mathrm{mg}$ ) and Quetiapine $100 \mathrm{mg}$. She was given Escitalopram for episodic depressive features. As she did not improve, Haloperidol $10 \mathrm{mg}$ was initiated. After two weeks, she exhibited features of tardive dyskinesia, and hence Haloperidol was discontinued. At present, she is maintained on Clozapine $200 \mathrm{mg}$. She was continued on Phenytoin sodium $300 \mathrm{mg}$ and Phenobarbital $60 \mathrm{mg}$ for seizure control. Even with this regime, she was not seizure-free. An attempt to switch to Carbamazepine was made but had to be terminated as she developed severe drug-induced rashes. She was not cooperative for psychological evaluation.

The radiological findings are provided in Figures 13.

\section{DISCUSSION}

DDMS is considered a rare disease which often presents in childhood $^{1}$, adolescence ${ }^{5,6}$ or young adults. ${ }^{7,8}$ After an extensive literature review, presentation beyond 50 years was found to have been reported only once. ${ }^{9}$ The predominant clinical presentation includes seizures, mental retardation, hemiplegia, and facial asymmetry. The probable suggested mechanism for DDMS is a cerebral insult which may have occurred in-utero or during early life which may cause the associated calvarial changes. Causes implicated include birth trauma, vascular events, hypoxia, and infections. ${ }^{10}$ Psychiatric manifestations have also been described, which often include psychotic features and episodic mood disorders. Cases of refractory schizoaffective disorders are frequently reported.

The case discussed here had psychiatric features suggestive of schizoaffective disorder, refractory seizure disorder, and mental retardation. The illness in the first year of her life would have contributed to development of the characteristic brain changes. The management of the patient will focus on control of seizures and her psychiatric symptoms. She may benefit from domiciliary physiotherapy.

Loss of neurons and their connections in the cerebral hemisphere is known as cerebral atrophy. Cerebral atrophy may be bilateral as in senile patients (diffuse atrophy) or neurocognitive diseases like Alzheimer's disease (lobar predominance of atrophy), or unilateral as in diseases causing ischaemic, traumatic, inflammatory, or infective insult to the brain parenchyma. ${ }^{11}$ The presence of unilateral hemiatrophy is a pointer to a narrow group of differential diagnoses like DDMS, Rassmussen's encephalitis, and Sturge-Weber syndrome. ${ }^{12}$ Asymmetry in size may also be due to an enlarged hemisphere as in unilateral hemimegalencephaly. ${ }^{13}$ In DDMS, the insult to the brain parenchyma occurs during the foetal period or in early childhood. It is characterized by hemiatrophy with ipsilateral midline shift, dilation of the ipsilateral lateral ventricle and dilated ipsilateral paranasal sinuses called pneumosinus dilatans. Ipsilateral calvarial thickening is also noted. ${ }^{14}$ The closest imaging differential diagnosis is Rassmussen's encephalitis, which does not show calvarial changes. Sturge Weber syndrome can be differentiated by the presence of pial angiomas and ipsilaterally enlarged choroid plexuses. ${ }^{11}$ In hemimegalencephaly, which is a hamartomatous overgrowth of one side of the cerebral hemisphere, the affected side shows a dysmorphic lateral ventricle, with a normal contralateral ventricle in the relatively smaller and normal cerebral hemisphere. ${ }^{15}$ 
Figures 1a-c: Axial T2 weighted images of the brain shows hemiatrophy with the involvement of the left frontal (arrow-head), parietal (small arrow), and temporal regions (curved arrow) with dilation of the ipsilateral lateral ventricle (broken arrow).

\section{Figure 1a}

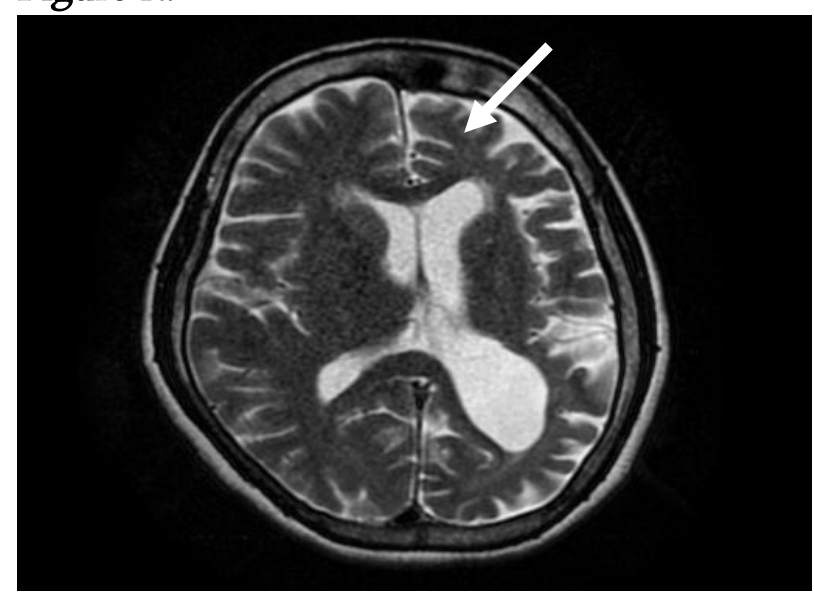

\section{Figure $1 b$}

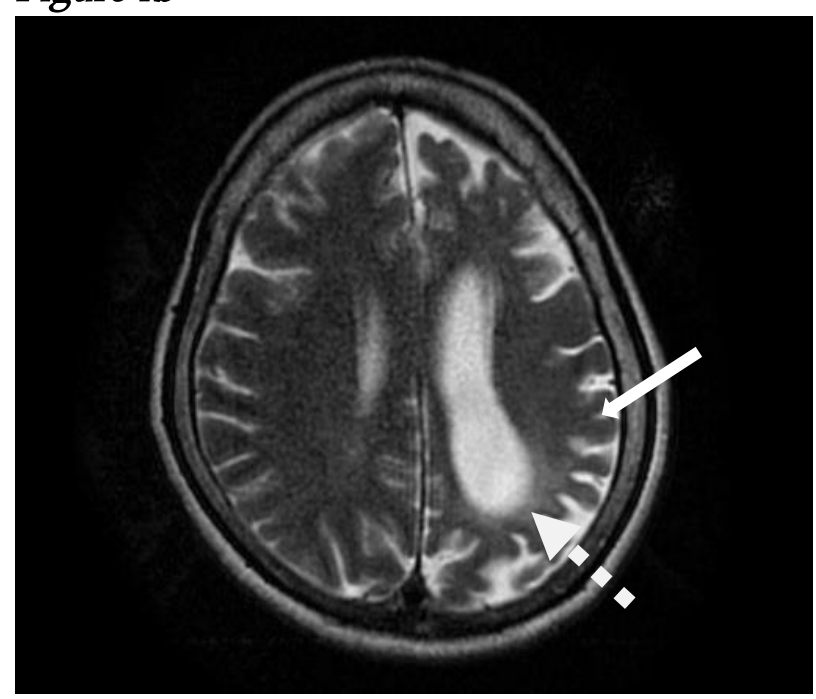

Figure 1c

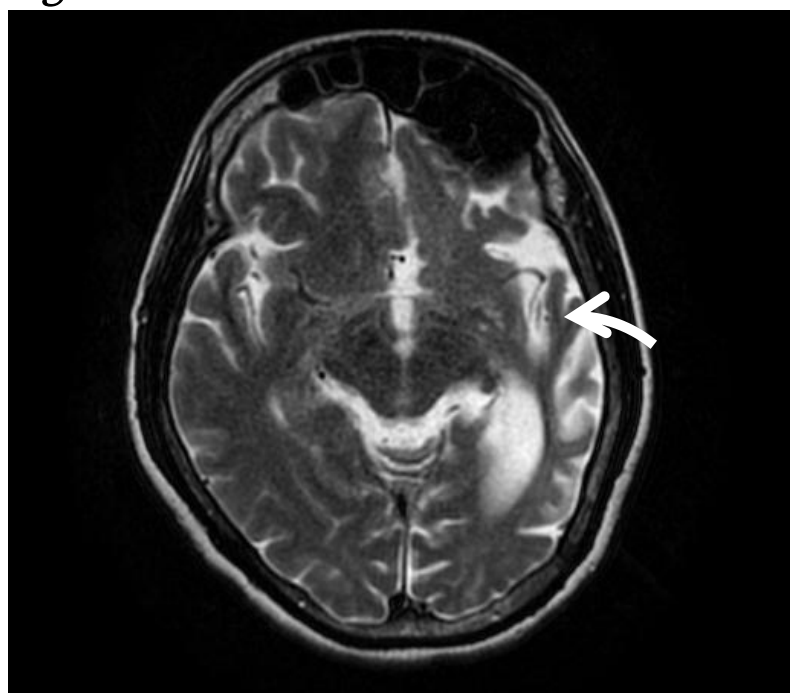

Figure 2: Sagittal T1 weighted image of the brain shows dilation of the left frontal sinus, suggestive of pneumosinus dilatans (small arrow).

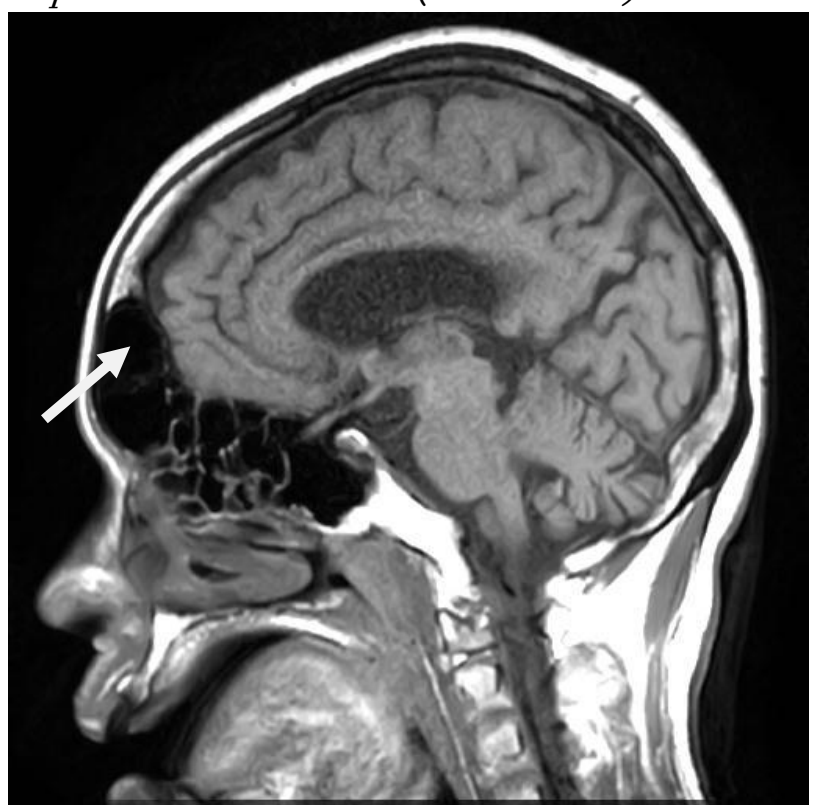

should strive to identify patients suffering from mental health diseases and provide their families necessary information on governmental assistance for treatment of such diseases. This will also help to identify any underlying organic cause for the psychiatric symptoms. The failure to do so significantly reduces the quality of life for these patients and their families. 
Figure 3: Coronal T2 weighted image of the brain shows dilation of the left frontal sinus, suggestive of pneumosinus dilatans (small arrow)

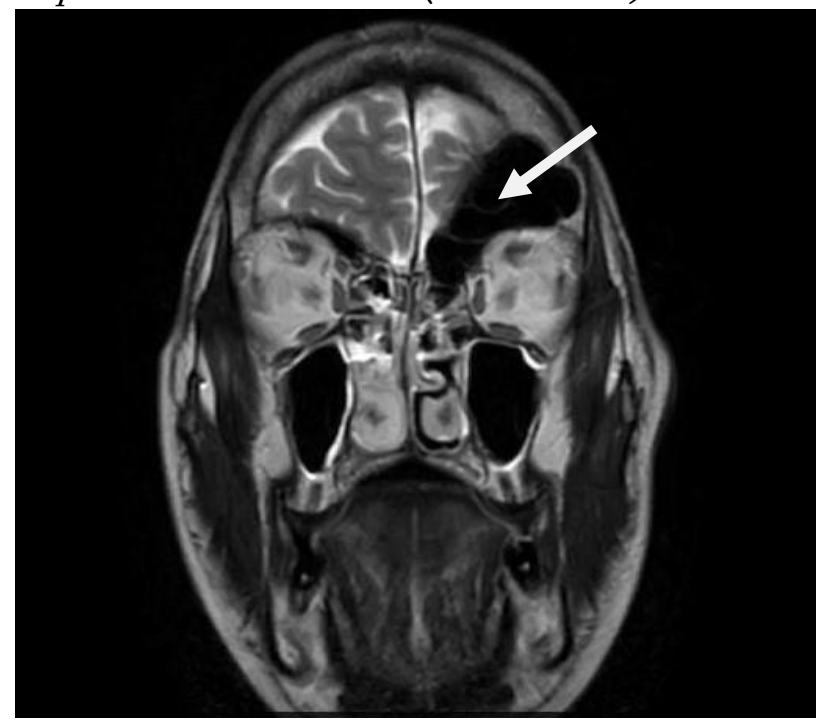

10. Sener RN, Jinkins JR, MRI of Craniocerebral Hemiatrophy. Clin Imaging 1992; 16(2):93-7.

11. Krueger CE, Dean DL, Rosen HJ, Halabi C, Weiner M, Miller BL, et al. Longitudinal rates of lobar atrophy in fronto temporal dementia, semantic dementia and Alzheimer's disease. Alzheimer Dis Assoc Disord 2010; 24(1):43-8.

12. Uduma, Felix U. Differential diagnose of cerebral hemiatrophy in childhood. A review of literature with illustrative report of two cases. Glob J Health Sci 2013; 5(3):195-207.

13. Alikhanov AA, Nikanorov Alu. Unilateral hemimegalencephaly and hemiatrophy of brain. Principles of computer tomographic differentiation. Zh Nevrol Psikhiatr Im S S Korsakova 1998; 98(11):26-9.

14. Behera MR, Patnaik S, Mohanty AK. Dyke-DavidoffMasson syndrome. J Neurosci Rural Pract 2012; 9(3):411-3.

15. Broumandi DD, Hayward UM, Benzian JM, Gonzalez I, Nelson MD. Best cases from the AFIP: Hemimegalencephaly. Radiographics 2004; 24(3):843-8.

Source of support: None

Conflict of interest: None declared

1. Dyke CG, Davidoff LM, Masson CB. Cerebral hemiatrophy and homolateral hypertrophy of the skull and sinuses. Surg Gynecol Obstet 1933; 57:588-602.

2. Roy U, Panwar A, Mukherjee A, Biswas D. Adult presentation of Dyke Davidoff Masson syndrome. A case report. Case Rep Neurol 2016; 8:1:20-6.

3. Asli DT, Ayse D, Tugba GC. Neurodevelopmental influences in psychosis: A case of left cerebral hemiatrophy and schizoaffective disorder. Klinik Psikofarmakol Bulteni 2013; 23:4:368-72.

4. Amann B, DelaIglesia C, McKenna P, Pomarol CE, Sanchez GM, Orth M. Treatment refractory schizoaffective disorder in a patient with DykeDavidoff-Masson Syndrome. CNS Spectrums 2009; 14(1):36-40.

5. Kumar S, Lakshmaiah V, Karthik NKC. A rare cause for seizures and mental retardation, Dyke Davidoff Masson Syndrome. Int J Biol Med Res 2011; 2(4): 1186 -8.

6. NdahIriwe JB, Cook E. Dyke Davidoff Masson Syndrome: A rare imaging case. Rwanda Medical Journal 2012; 69(1):54-6.

7. Yerdelen D, Filiz K, Zafer K. Dyke-Davidoff-Masson Syndrome. Neurosurgery Quarterly 2009; 19: 59-61.

8. Sharma S, Goyal D, NegiI A, Sood RG, Jhobta A, Surya M. Dyke-Davidoff Masson Syndrome. Ind J Radiol Imag 2006; 16(2):165-6.

9. Biçici V, Ekiz T, Bingol I, Hatipoglu C. Dyke-DavidoffMasson syndrome in adulthood. A 50-year diagnostic delay. Neurology 2014; 83:11-21.
First submitted: $1^{\text {st }}$ August 2017

Published online: $10^{\text {th }}$ January 2018 